\title{
Analysis of Current Density and Specific Absorption Rate in Biological Tissue Surrounding Transcutaneous Transformer for an Artificial Heart
}

\author{
Kenji Shiba*, Member, IEEE, Masayuki Nukaya, Toshio Tsuji, Member, IEEE, and Kohji Koshiji, Member, IEEE
}

\begin{abstract}
This paper reports on the current density and specific absorption rate (SAR) analysis of biological tissue surrounding an air-core transcutaneous transformer for an artificial heart. The electromagnetic field in the biological tissue is analyzed by the transmission line modeling method, and the current density and SAR as a function of frequency, output voltage, output power, and coil dimension are calculated. The biological tissue of the model has three layers including the skin, fat, and muscle. The results of simulation analysis show SARs to be very small at any given transmission conditions, about $2-14 \mathrm{~mW} / \mathrm{kg}$, compared to the basic restrictions of the International Commission on nonionizing radiation protection (ICNIRP; $2 \mathrm{~W} / \mathrm{kg}$ ), while the current density divided by the ICNIRP's basic restrictions gets smaller as the frequency rises and the output voltage falls. It is possible to transfer energy below the ICNIRP's basic restrictions when the frequency is over $250 \mathrm{kHz}$ and the output voltage is under $24 \mathrm{~V}$. Also, the parts of the biological tissue that maximized the current density differ by frequencies; in the low frequency is muscle and in the high frequency is skin. The boundary is in the vicinity of the frequency $600-1000 \mathrm{kHz}$.
\end{abstract}

Index Terms-Artificial heart, current density, electromagnetic induction, energy transmission, specific absorption rate (SAR).

\section{INTRODUCTION}

A N ARTIFICIAL heart system is composed of the blood pump, a control device, and the energy source. The places to set up these component parts have changed from inside the body to outside the body; however, most of the commercially available artificial heart systems transfer energy by means of wires penetrating the abdomen's or chest's skin from an external source [1]-[3]. We have been developing the transcutaneous energy transmission system (TETS), which transfers energy by

Manuscript received August 28, 2006. This work was supported in part by the Electric Technology Research Foundation of Chugoku, the experiment and research grant for fiscal 2004, and a Grant-in-Aid for Scientific Research (Wakate(B), No. 17760234) in the Ministry of Education, Science, Sports, and Culture. Asterisk indicates corresponding author.

*K. Shiba is with the Graduate school of Engineering, Hiroshima University, 1-4-1 Kagamiyama, Higashi-Hiroshima 739-8527, Hiroshima, Japan (e-mail: shiba@ bsys.hiroshima-u.ac.jp).

M. Nukaya is with the Graduate school of Engineering, Hiroshima University, Higashi-Hiroshima, Hiroshima, Japan.

T. Tsuji is with the Graduate school of Engineering, Hiroshima University, Higashi-Hiroshima 739-8527, Hiroshima, Japan (e-mail: tsuji@bsys.hiroshima-u.ac.jp).

K. Koshiji is with Tokyo University of Science, Chiba 278-8510, Japan (e-mail: koshiji@ee.noda.tus.ac.jp).

Digital Object Identifier 10.1109/TBME.2007.900550 means of electromagnetic induction between two coils of a transcutaneous transformer placed face-to-face on each side of the abdomen's or chest's skin [4]-[12]. This method can allow patients mobility, improved quality of life (QOL), and reduced risk of infection relative to percutaneous connections. Various types of transcutaneous transformers exist, such as air-core [4]-[9], air-core with amorphous wires [10] and externally coupled [11]. The air-core transcutaneous transformer is thin and lightweight; therefore, it is possible to implant it in an aesthetically pleasing manner. While the externally coupled one has a high magnetic coupling factor and maintains stable operation with high transmitting efficiency due to the body's movement, it is difficult to implant due to its transformer's internal coil's protrusion from the body's surface, forming a skin tunnel. Therefore, many researchers have examined and developed an air-core transcutaneous transformer.

The first air-core transcutaneous transformers were developed in the early 1960s [4]. Some air-core transcutaneous transformers have been studied to achieve a more efficient design capable of operating over a wide range of parameters and conditions, and achieve a satisfactory level of performance. To make this method practical, however, TETS' electromagnetic influence on biological tissue has to be investigated.

Some people have studied how the electromagnetism influences biological tissue. For example, Schuder estimated the power loss in the tissue using numeric integration [12]. Koshiji estimated the absorbable power in the biological tissue [5]. These studies, however, are not a detailed estimation but a simple calculation, which assumes the biological tissues are a homogeneous substance, such as water. Also, these studies do not consider biological tissue's frequency characteristics. In addition, they do not examine the electromagnetic effect on the body when the transmission parameters such as frequency, output voltage, output power, and coil dimension vary.

Electromagnetic influences on biological tissue include thermal effect and stimulant action [13]. Thermal effect means the temperature increase due to the Joule heat generated in the biological tissue, and stimulant action means the neural and muscle excitation due to the induced current. In general, the specific absorption rate (SAR), watts per kilograms, which is defined as the power of an electromagnetic wave absorbed into biological tissue per unit mass of $1 \mathrm{~kg}$, often is used as an index of the thermal effect. Current density, amperes per square meter, which is defined as the current magnitude per unit area of $1 \mathrm{~m}^{2}$, often is used as an index of the stimulant action. These indices have the basic restrictions defined by the 


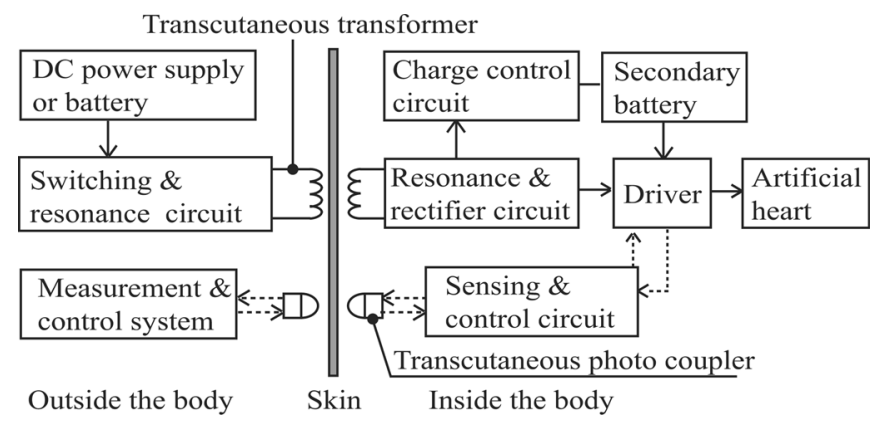

Fig. 1. Block diagram of the energy transmission system for a total artificial heart.

International Commission on nonionizing radiation protection (ICNIRP) [14]. Therefore, the authors have studied the thermal effect caused by electromagnetic waves and have analyzed SAR surrounding an externally coupled type of transformer via the transmission-line modeling (TLM) method at a frequency of only $100 \mathrm{kHz}$ [15]. The evaluations of SAR and current density surrounding an air-core transcutaneous transformer have not been investigated and safe transmission conditions have not been known.

In this paper, we analyze the SAR and current density in the biological tissue surrounding the air-core transcutaneous transformer and derive the safe transmission conditions include transmission frequency and power.

\section{METHODS}

\section{A. Energy Transmission System}

Fig. 1 shows a block diagram of the TETS. The direct current supplied by a dc power source or a secondary battery outside the body is changed to an alternating current of $100-1000 \mathrm{kHz}$ using a switching circuit. The changed ac power is then transmitted inside the body using electromagnetic induction between two air-core coils placed inside and outside the body (transcutaneous transformer). Here, the air-core coils are thin, lightweight, and pancake-shaped coils. The ac power transmitted inside the body is changed back to dc power using an implanted rectifier circuit. Then the dc power is supplied to the artificial heart's actuator and the back-up secondary battery [16], [17]. The energy transmission system used here has high-breakdown voltage capacitors in series with coils. This is because a large amount of power can be transferred with low input voltage by resonance with the coils.

We have designed and developed an air-core transcutaneous transformer for an artificial heart that has the following three features [18]: 1) the energy transmission efficiency is high (no less than 90\%); 2) the input voltage is low (not more than $50 \mathrm{~V}$ ); and 3) the internal coil's outside diameter is small (not more than $7 \mathrm{~cm}$ ). High efficiency is needed to reduce the temperature rise of the coil, a low input voltage is required for reliability, and it is desirable for an internal coil's diameter to be small, lightweight, and thin when considering the strain placed upon the patient-especially the skin's adiemorrhysis surrounding the coils.

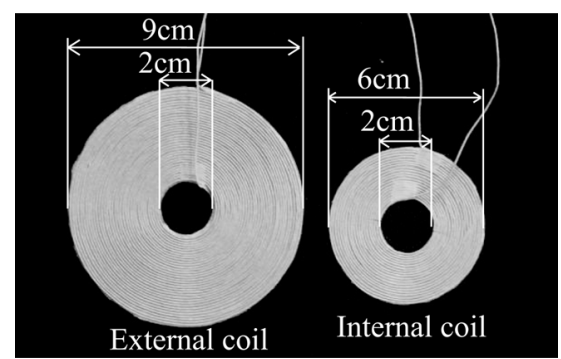

Fig. 2. Air-core transcutaneous transformer used in the experiment.

Fig. 2 shows the air-core transcutaneous transformer examined in this study. It consists of the external (primary) coil set outside the body and the internal (secondary) coil implanted under the skin. The external coil has an outside diameter of $90 \mathrm{~mm}$ (35 turns), an inside diameter of $20 \mathrm{~mm}$, and a thickness of $1 \mathrm{~mm}$. The internal coil has an outside diameter of 60 $\mathrm{mm}$ (20 turns), an inside diameter of $20 \mathrm{~mm}$, and a thickness of $1 \mathrm{~mm}$. The coils are made of copper litz-wire in consideration of the skin effect. An ac-to-ac energy transmission efficiency of $94.5 \%$ (maximum) is obtained between the frequencies of $500-800 \mathrm{kHz}$. This paper uses the transcutaneous transformer as its basic air-core transformer model and estimates the SAR and the current density.

\section{B. Influence of Electromagnetism}

The ICNIRP provides basic restrictions on SAR between the frequencies of $100 \mathrm{kHz}-10 \mathrm{MHz}$ to prevent whole-body heat stress and excessive localized tissue heating [14]. In addition, basic restrictions are also provided on current density to prevent effects on nervous system functions. This secondary section describes the method of SAR's and current density's derivation. Each restriction is also described.

1) Estimation of SAR: SAR is expressed by

$$
\mathrm{SAR}=\frac{\sigma E^{2}}{\rho}
$$

where $E$ is the electric field's root mean square (volts per meters), $\sigma$ is the biological tissue's electrical conductivity (siemens per meters) and $\rho$ is the biological tissue's density (kilograms per cubed meters). SAR is evaluated by two methods: one experimental and one analytical. In the experimental method, the electrical field in a liquid phantom is measured [19] or the temperature rise in a solid phantom is measured and commuted to SAR [20]. It is difficult, however, to correctly measure the temperature rise with these methods because there is not only a temperature increase in the phantom due to the electromagnetic field but also a temperature increase in the transcutaneous transformer due to copper loss. This paper numerically analyzes SAR.

Table I shows basic restrictions on SAR defined by the ICNIRP. These basic restrictions are divided into occupational and general public exposures. The occupationally exposed population consists of adults who are generally exposed under known conditions and are trained to be aware of the potential risk and to take appropriate precautions. By contrast, the general public comprises individuals of all ages and of varying health status, 
TABLE I

BASIC RESTRICTIONS FOR TIME VARYING ELECTRICAL AND MAGNETIC FIELDS (ICNIRP)

\begin{tabular}{lccc}
\hline \hline & Frequency range & $\begin{array}{c}\text { Localized SAR } \\
\text { (head and trunk) } \\
(\mathrm{W} / \mathrm{kg})\end{array}$ & $\begin{array}{c}\text { Current density } \\
\text { for head and trunk } \\
\left(\mathrm{mA} / \mathrm{m}^{2}\right)\end{array}$ \\
\hline $\begin{array}{l}\text { Occupational } \\
\text { exposure }\end{array}$ & $100 \mathrm{k}-10 \mathrm{MHz}$ & 10 & $f / 100, f(\mathrm{~Hz})$ \\
$\begin{array}{l}\text { General public } \\
\text { exposure }\end{array}$ & $100 \mathrm{k}-10 \mathrm{MHz}$ & 2 & $f / 500, f(\mathrm{~Hz})$ \\
\hline \hline
\end{tabular}

and may include particularly susceptible groups or individuals. This paper adopts basic restriction for general public exposure $(2 \mathrm{~W} / \mathrm{kg})$.

2) Estimation of Current Density: Current density $J$ is expressed by (2), [21], [22]

$$
J=\pi R f \sigma \mu H_{\text {ave }}
$$

where $\sigma$ is the biological tissue's electrical conductivity (siemens per meters), $f$ is the frequency (hertz), $\mu$ is the magnetic permeability (hertz per meters) and $R$ is the radius of the loop for current induction (meters). $H_{\text {ave }}$ is expressed by

$$
H_{\text {ave }}=\frac{1}{R} \int_{0}^{R} H d R
$$

where $H$ is the magnetic field's root mean square (amperes per meters).

Current density is also evaluated by two methods: one experimental and one analytical. The experimental method measures the current that flows from the head to the ground using a biological phantom when there is an electric field source overhead [23]. In this study, however, magnetic fields are radiated locally in parts of the human body and the eddy currents flow, so it is difficult to obtain accurate values inside the body unless human body is dissected and measured. This paper numerically analyzes current density.

The ICNIRP also defines basic restrictions on current density. This paper adopts the basic restrictions for general public exposure $\left(f / 500 \mathrm{~A} / \mathrm{m}^{2}\right)$ and occupational exposure $\left(f / 100 \mathrm{~A} / \mathrm{m}^{2}\right)$.

\section{Analysis Using an Electromagnetic Simulator}

1) Method of Analysis: "Micro-Stripes" (Flomerics, Japan branch), the electromagnetic simulator employing the TLM method [24]-[26], is used to analyze SAR and current density. The TLM method has very powerful tools for field computations. They are based on an analogy between the electromagnetic field and the transmission lines' grid. A mathematical derivation of the TLM method can be directly obtained from a full wave time-domain solution to Maxwell's equations.

The procedure of analysis using Micro-Stripes is as follows. First, a model similar to human configuration and electrical characteristic is created. Next, this model is divided into small cells by mesh and the electric field $E$, magnetic field $H$, and SAR [calculated from electric field $E$ and (1)] are calculated. Current density $J$ is then estimated from the magnetic field $H$ obtained from the previous analysis and (2).

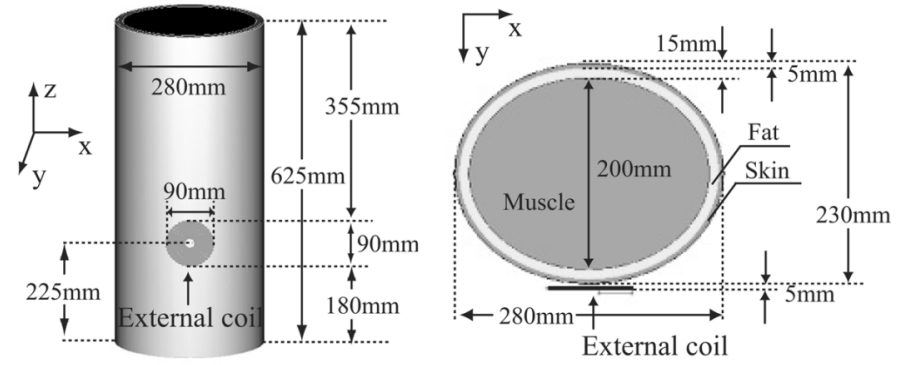

(a)

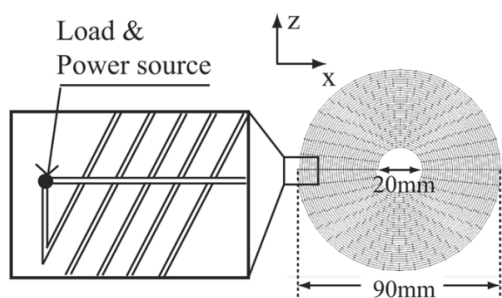

(b)

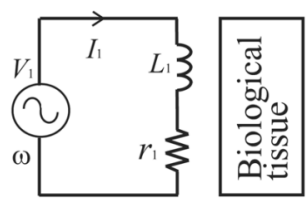

(c)
Fig. 3. (a) Analyzed model. (b) Magnified figure of the external coil. (c) Equivalent circuit of the analyzed model.

2) Model for Numerical Analysis: A model for numerical analysis is shown in Fig. 3(a). The body's trunk is modeled to an elliptical cylinder with: minor axis: $230 \mathrm{~mm}$; major axis: $280 \mathrm{~mm}$; and height: $625 \mathrm{~mm}$. The biological tissue has three layers: skin (a thickness of $5 \mathrm{~mm}$ ), fat (a thickness of $10 \mathrm{~mm}$ ), and muscle (the rest). The length of the trunk is the average for Japanese men [27]. The air-core transcutaneous transformer (outside diameter: $90 \mathrm{~mm}$; inside diameter: $20 \mathrm{~mm}$ ) is placed 5 $\mathrm{mm}$ away from the trunk. The supply source and the resistance are placed at the coil's terminal shown in Fig. 3(b).

3) Analysis Condition: The analysis model's equivalent circuit is shown in Fig. 3(c). The magnitude of $V_{1}$ remains constant at $1000 \mathrm{~V}$, and the input current $I_{1}$ is adjusted by $r_{1}$ to be the amplitude obtained by the theoretical analysis. The model for numerical analysis by TLM had grids of $1 \mathrm{~mm}$ in the coil's vicinity, and from 3 to $23 \mathrm{~mm}$ in other regions.

Fig. 4 shows the electrical characteristics of biological tissue: (a) is the conductivity and (b) is the relative permittivity. This paper uses the conductivity and relative permittivity values defined by Institute for Applied Physics "Nello Carrara" (IFAC) [28]-[31]. An average value of $1000 \mathrm{~kg} / \mathrm{m}^{3}$ is used to represent the density of biological tissue consisting of skin, fat, and muscle [32], and its relative permeability is 1 .

SAR and current density are analyzed: 1 ) as a function of the output power 5-20 W (5 W each) with a constant frequency of $600 \mathrm{kHz} ; 2$ ) as a function of the frequencies $200-1000 \mathrm{kHz}$ ( $200 \mathrm{kHz}$ each) and output voltages of $12 \mathrm{~V}$ and $24 \mathrm{~V}$ with a constant output power of $20 \mathrm{~W}$, and 3 ) as a function of the coils' dimension with a constant output power of $20 \mathrm{~W}$. Here, the output voltages of 12 and $24 \mathrm{~V}$ are the basic drive voltages of the artificial heart that is currently being developed or utilized.

\section{Comparison of Analytical to Measured Value}

Before a detailed analysis it must be examined whether the electromagnetic field's analytical values are correct. Therefore, 


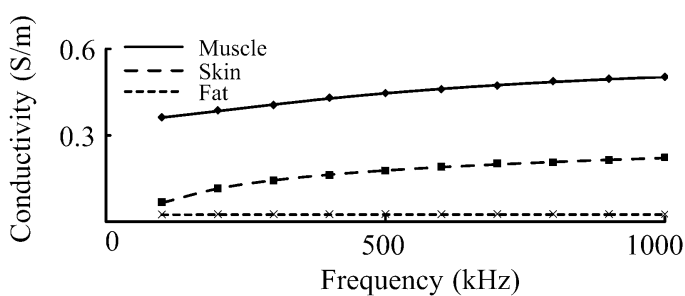

(a)

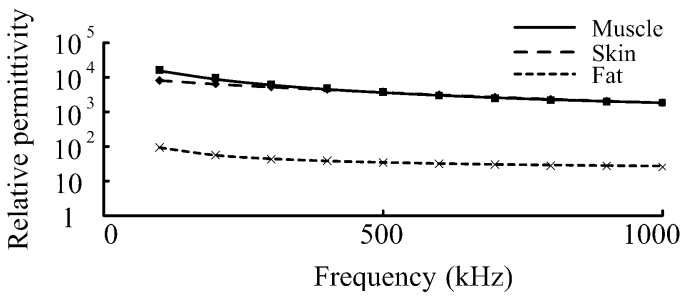

(b)

Fig. 4. (a) Conductivity and (b) relative permittivity values as defined by IFAC.

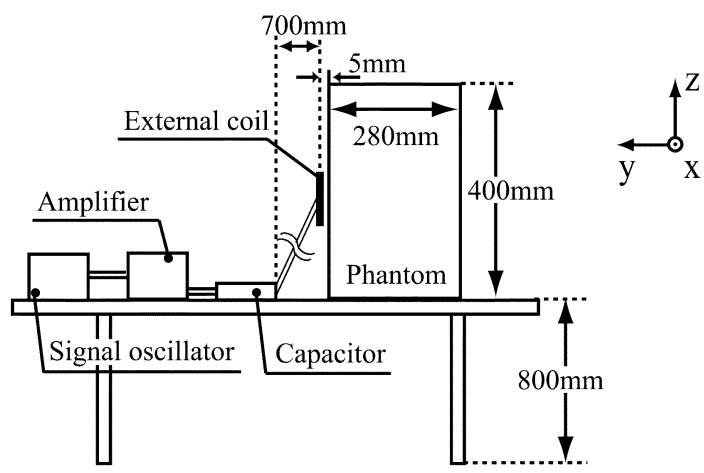

(a)

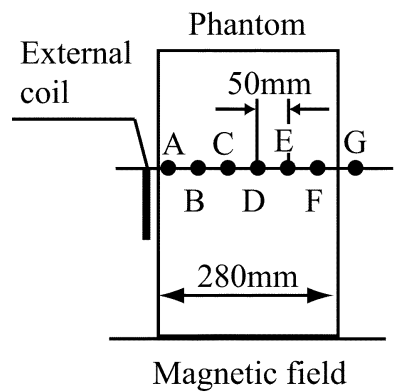

(b)

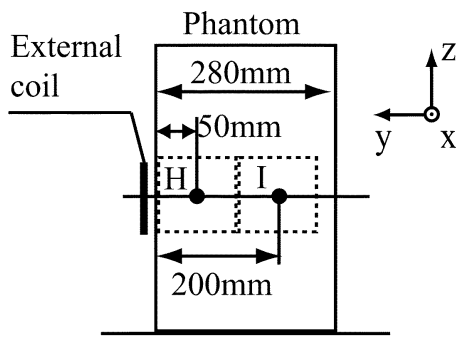

Electric field
Fig. 5. (a) Arrangement to measure electrical and magnetic fields. (b) Magnetic field's measuring point. (c) Electric field's measuring point.

the electric and magnetic strength under the same conditions as the analytical model are measured and compared to the analytical values.

1) Measurement Method: Fig. 5(a) shows the measuring arrangement. Contained in a circular container with a height of $40 \mathrm{~cm}$, a diameter of $28 \mathrm{~cm}$, and a thickness of $2 \mathrm{~mm}$ polypropylene is the biological phantom adjusted to the biological tissue's electrical characteristics. The ac voltage output from a signal oscillator (IWATSU, SG-4105) is amplified by a high-speed amplifier (NF, 4025), and is transferred to the transcutaneous transformer through a polypropylene film capacitor (NISSEI, MPE102, APS101). The transcutaneous transformer's external coil is placed $5 \mathrm{~mm}$ away from the biological phantom. The experiment measured the electrical field $E$ and the magnetic field $H$ with a frequency of $600 \mathrm{kHz}$, an output voltage of $24 \mathrm{~V}$ and output power of $20 \mathrm{~W}$. This measurement was run in a radio anechoic chamber (Hiroshima-techno-plaza, $6.8 \mathrm{~m} \times 2.6 \mathrm{~m} \times 2.6 \mathrm{~m}$ ) that had a shield performance of $80 \mathrm{~dB}$ (at $150 \mathrm{kHz}$ to $30 \mathrm{MHz}$ ). The measurement object is set on a nonconductive table (height $80 \mathrm{~cm}$ ) placed in the radio anechoic chamber.

In the measurement of the magnetic fields, the values measured by the magnetic near field probe [HP, 11941A: $3.5 \mathrm{~cm} \times 0.3 \mathrm{~cm} \times 0.4 \mathrm{~cm}$ (sensor), $3.76 \mathrm{~cm} \times$ $26.45 \mathrm{~cm} \times 2.14 \mathrm{~cm}$ (body)] are displayed by the spectrum analyzer (Micronix, MSA338). The measuring points are shown in Fig. 5(b). The magnetic fields are measured on the external coil's edge axis [the distance from the external coil = 0-30 $\mathrm{cm}$ by $5 \mathrm{~cm}$ (Points A-G)].

In the measurement of the electric fields, the values measured by the electric field probe [HOLADAY, HI-4421 G : $6.5 \mathrm{~cm} \times 6.5 \mathrm{~cm} \times 6.5 \mathrm{~cm}$ (cube), $3.8 \mathrm{~cm}$ (sensor covers)] are displayed by the electric receiver (HOLADAY, HI-4400). The measuring points are shown in Fig. 5(c). The electric fields are measured on the external coil's center axis [the distance from the external coil $=5 \mathrm{~cm}, 20 \mathrm{~cm}$ (Points H, I)]. The dashed lines show the electric field probe's size.

2) Characteristics of Biological Phantom: The biological phantom used in the experiment is adjusted to have the same electrical characteristics as muscle between the frequencies of 100 and $1000 \mathrm{kHz}$, which accounts for a large share of the body. The biological phantom consists of deionized water, sodium chloride, boric acid (preservative agent), TX-151 (thickening agent), and polyethylene powder [33]. Its conductivity and relative permittivity are controlled with additional rates of sodium chloride and polyethylene powder, respectively. In this paper, the mass ratios are: deionized water, 87.5 ; sodium chloride, 0.5; boric acid, 1.0; TX-151, 2.2; polyethylene powder, 8.8.

The conductivity and relative permittivity are measured to examine whether the phantom's electrical characteristics are correctly simulated. First, the phantom was inserted between the parallel aluminum plates (distance between the plates is $15 \mathrm{~mm}$, and they are $80 \mathrm{~mm}$ square). Next, the resistance $R$ and reactance $X$ are measured using a high-frequency digital power meter equipped with voltage and current meters (Yokogawa, PZ4000). The measurement frequencies are from $100 \mathrm{kHz}$ to $1000 \mathrm{kHz}$ by $100 \mathrm{kHz}$. After the measurement, the results of the resistance $R$ and reactance $X$ were substituted into the following (4) and (5), and the conductivity $\sigma$ and relative permittivity $\varepsilon_{\mathrm{s}}$ were calculated:

$$
\begin{aligned}
\sigma & =\frac{d}{S R} \\
\varepsilon_{\mathrm{s}} & =\frac{d}{\varepsilon_{0} S \omega X}
\end{aligned}
$$

where $\omega$ is the angular frequency, $d$ is the distance between plates, $S$ is the plate area, and $\varepsilon_{0}$ is the electric constant. 


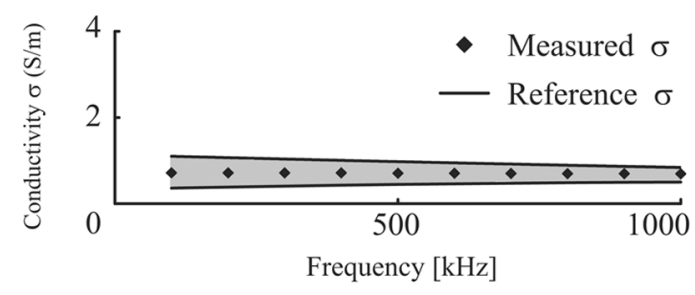

(a)

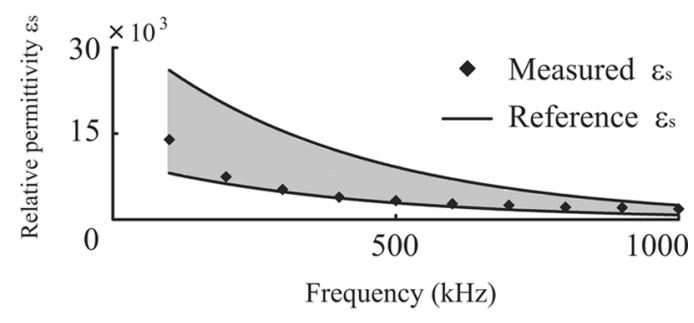

(b)

Fig. 6. Measured (a) conductivity and (b) relative permittivity.

\section{RESULTS AND DISCUSSION}

\section{A. Results of Measured Electric and Magnetic Field}

Fig. 6 shows the phantom's conductivity and relative permittivity measurement results. The full line and the range of the gray are the various reference values [28]-[31], [34]-[36] and the marks are the measured values. The relative permittivity and conductivity almost correspond with the various reference values. Therefore, this phantom was used in this experiment.

The measurement results of the magnetic and electric fields' strength are shown in Fig. 7(a) and (b). The electric field strength shows the maximum value in the dashed lines of Fig. 5(c). As a result of Fig. 7, the measured magnetic field strengths almost correspond with the analytical values. Therefore, it is thought that the analytical results of the current density are correct, while the measured electric field strengths are three times as large as the analytical values at measuring point I. This occurs because the conducting wire between the voltage source and the coil produces high electric fields; the voltage source was set at a distance of $0.7 \mathrm{~m}$ from the external coil in the experiment [outlined in Fig. 5(a)] whereas the voltage source was set on the coil in the analysis [outlined in Fig. 3(b)]. Hence, according to the electrical field's measured value being three times as large as its analytical values, it is thought that the actual SAR would be nine times as large as its analytical values due to (1). The following analysis, therefore, also considers the increased values of SAR (nine as large as its analytic value).

\section{B. Localized SAR}

1) Analysis When the Output Power is Varied: The localized SAR was analyzed when the output power was varied with the most efficient frequency of $600 \mathrm{kHz}$. The localized SAR distribution with the frequency of $600 \mathrm{kHz}$ is shown in Fig. 8. (a) is the localized SAR distribution of a $y-z$ plane through the analysis model's central axis, and (b) is the localized SAR distribution of an $x-y$ plane; $z=225 \mathrm{~mm}$. These results show that the localized SAR is large near the external coil, and its maximum value appears in the skin layer which has a distance from the external coil of $5 \mathrm{~mm}$. Here, the value in the fat layer is two-thirds of that in the skin layer, and the value in the muscle

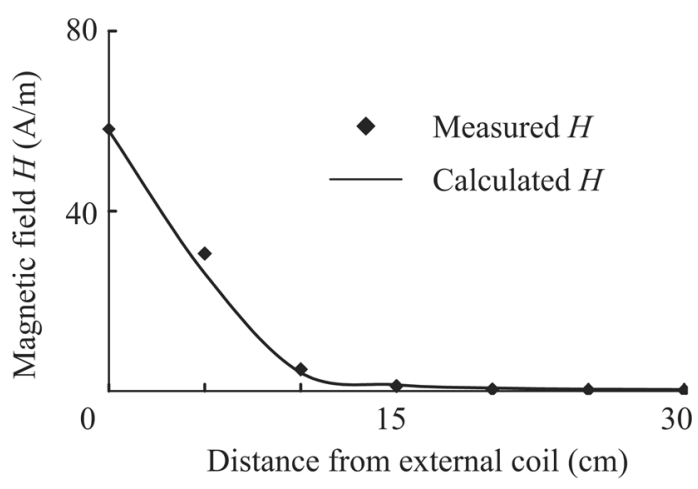

(a)

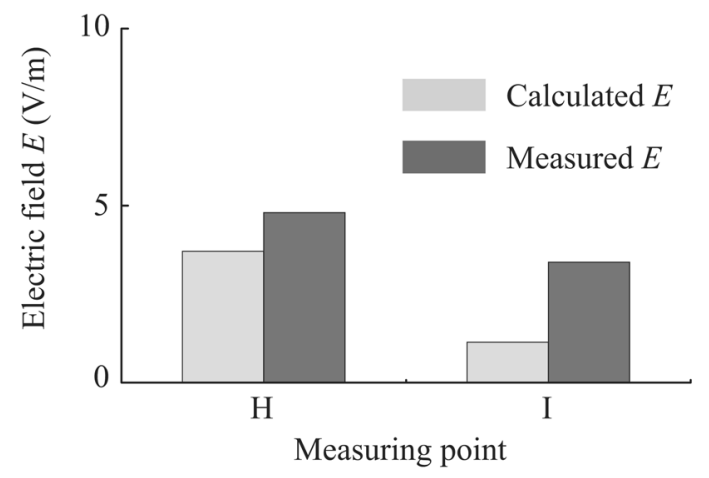

(b)

Fig. 7. (a) Comparisons between measured and calculated magnetic field strength. (b) Comparisons between measured and calculated electric field strength.
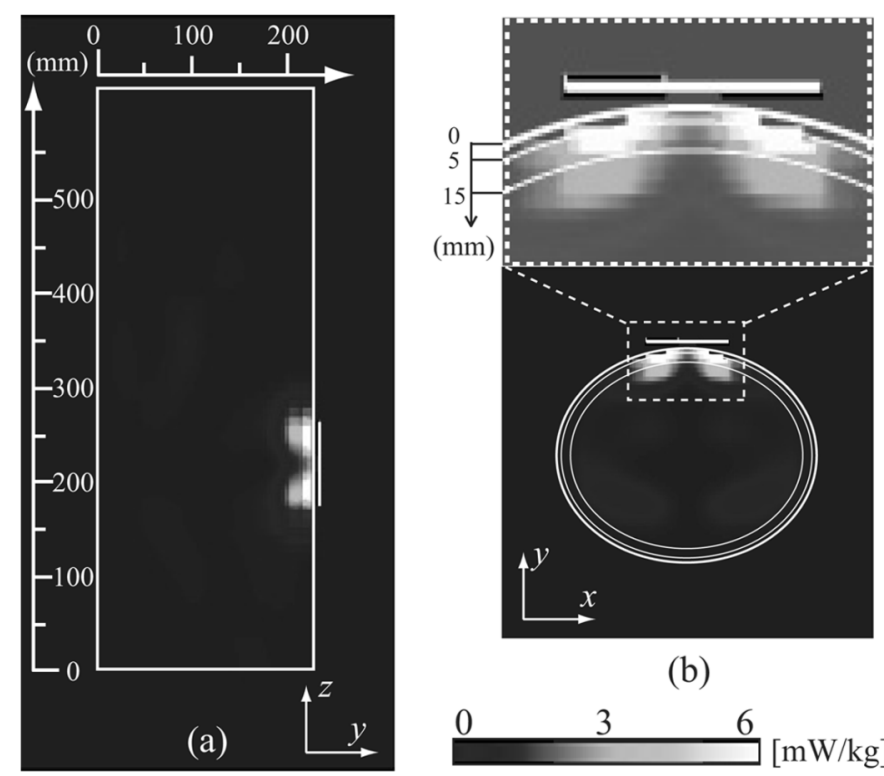

(b)

Fig. 8. (a) Localized SAR distribution of a $y-z$ plane through the analysis model's central axis. (b) The localized SAR distribution of an $x-y$ plane; $z=$ $225 \mathrm{~mm}$.

layer is one-third of that in the skin layer. The maximum value is $8.4 \mathrm{~mW} / \mathrm{kg}$ (increased value: $75.6 \mathrm{~mW} / \mathrm{kg}$ ). This value falls well below the ICNIRP's basic restriction $(2 \mathrm{~W} / \mathrm{kg})$.

Next, Fig. 9(a) shows the analytical results of the maximum localized SAR as a function of each output power. In addition, the voltage across the external coil $V_{L}$ is shown in Fig. 9(a) with thick lines. These results show a difference in SAR between the output powers of 5 and $20 \mathrm{~W}$ of $0.38 \mathrm{~mW} / \mathrm{kg}$; therefore, SAR 


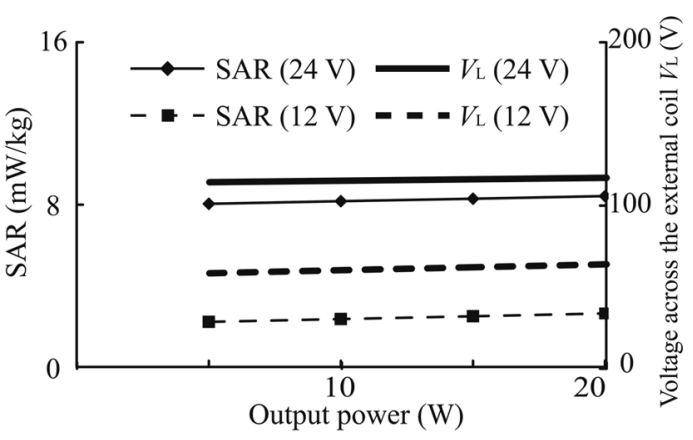

(a)

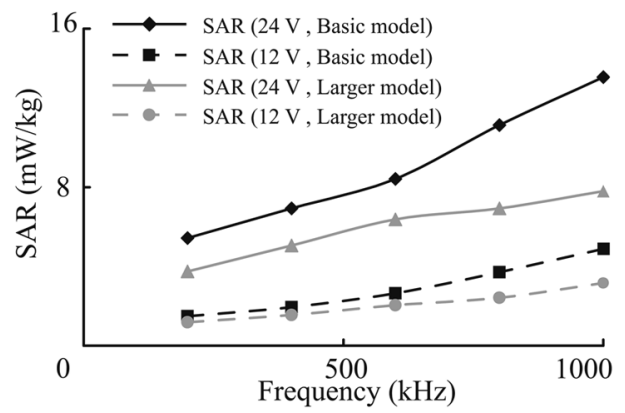

(b)

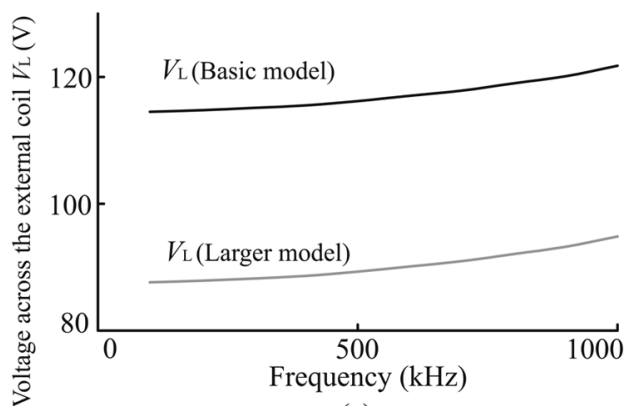

(c)

Fig. 9. (a) Maximum SAR as a function of the output power. (b) Maximum SAR as a function of the frequency. (c) The voltage across the external coil as a function of the frequency.

is constant even the output power is varied. The voltage across the external coil was also constant even the output power was varied. This happens because the input voltage is changed; however, the external coil's current, which is directly proportional to the voltage across the external coil, is constant because of the capacitors in series with the coils when the output power changes.

2) Analysis When the Frequency and Output Voltage Are Varied: The analytical results of the maximum localized SAR as a function of each frequency are shown in Fig. 9(b). The full line indicates an output voltage of $24 \mathrm{~V}$, the dashed line indicates an output voltage of $12 \mathrm{~V}$ and the mark indicates the analytical point. In addition, the voltage across the external coil with an output voltage of $24 \mathrm{~V}$ is shown in Fig. 9(c). These results show that the SAR gets larger as the frequency and output voltage rise. The maximum value is $14 \mathrm{~mW} / \mathrm{kg}$ (increased value: $126 \mathrm{~mW} / \mathrm{kg}$ ), and falls well below the ICNIRP's basic restrictions ( $2 \mathrm{~W} / \mathrm{kg}$ ). Comparing the results of the SAR with the voltage across the external coil, their slopes correspond very well. It is thought that the SAR depends on the voltage across the external coil.

3) Analysis When the Coil's Diameter Is Varied: The voltage across the external coil is in inverse proportion to the mutual inductance between the coils. Hence, it is necessary to increase the mutual inductance to reduce the voltage across the external coil.
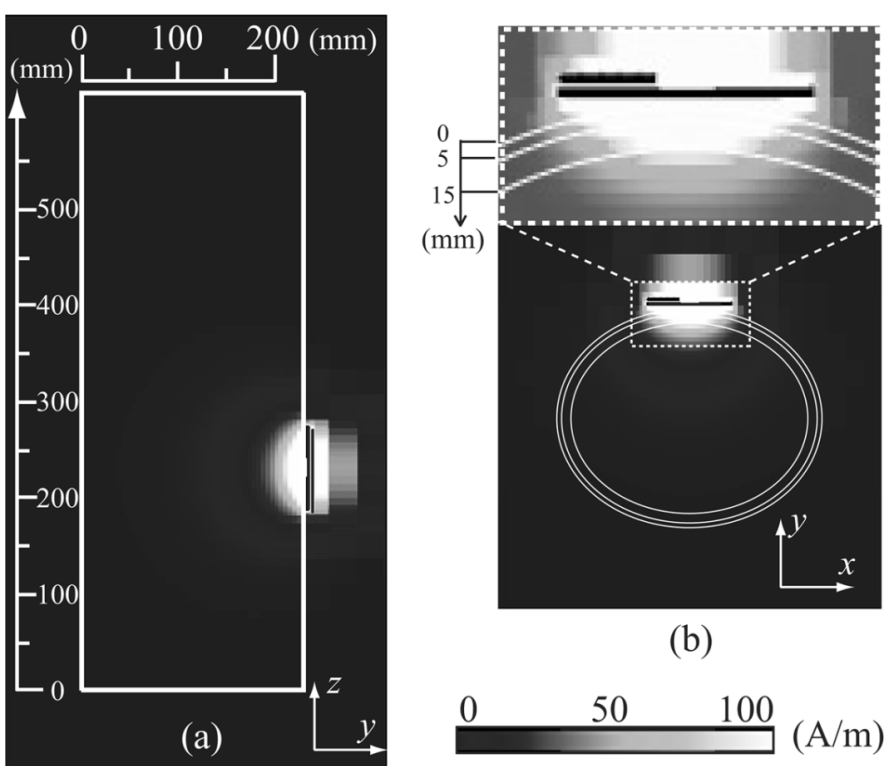

(b)

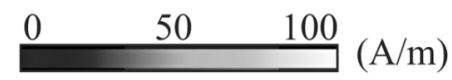

Fig. 10. (a) Magnetic field distribution of a $y-z$ plane through the analysis model's central axis. (b) The magnetic field distribution of an $x-y$ plane; $z=$ $225 \mathrm{~mm}$.

Therefore, in order to increase the mutual inductance, a model in which the transcutaneous transformer's dimensions were multiplied by 1.1 was analyzed (large model: the external coil's diameter is $100 \mathrm{~mm}$ and internal coil's is $70 \mathrm{~mm}$ ).

The analytical results of the maximum localized SAR as a function of each frequency are shown in Fig. 9(b) with the gray line. In addition, the voltage across the external coil with an output voltage of $24 \mathrm{~V}$ is shown in Fig. 9(c) with the gray line. These results show that SAR was reduced compared to the basic model, as was the voltage across the external coil. Therefore, it is confirmed that making the coil diameter larger effectively reduces SAR. In addition, it is confirmed that SAR is directly proportional to the voltage across the external coil and that SAR could be lowered by designing an external coil with a lower voltage.

\section{Current Density}

1) Analysis When the Output Power is Varied: The current density was analyzed when the output power was varied with the most efficient frequency of $600 \mathrm{kHz}$. The magnetic field distribution with a frequency of $600 \mathrm{kHz}$ is shown in Fig. 10. Fig. 10(a) is the magnetic field distribution of a $y-z$ plane through the analysis model's central axis and Fig. 10(b) is the distribution of an $x-y$ plane; $z=225 \mathrm{~mm}$. Calculating the current density from these results, its maximum value is in the muscle layer whose distance from the external coil is $20 \mathrm{~mm}$.

Next, the analytical results of the maximum current density as a function of each output power are shown in Fig. 11(a). In addition, the external coil's current $I_{1}$ is shown in Fig. 11(a) with thick lines. From these results, the difference in current density between the output powers of 5 and $20 \mathrm{~W}$ is $0.067 \mathrm{~A} / \mathrm{m}^{2}$. Current density is almost constant even when the output power was varied. The external coil's current is also constant even the output power is varied.

2) Analysis When the Frequency and Output Voltage Are Varied: The analytical results of the maximum current density as a function of each frequency are shown in Fig. 11(b). The long 


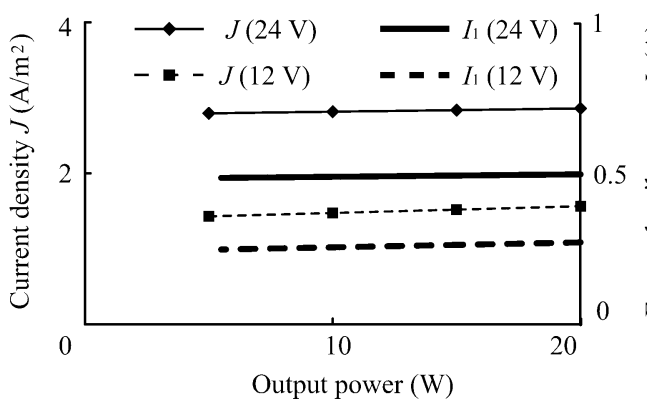

(a)

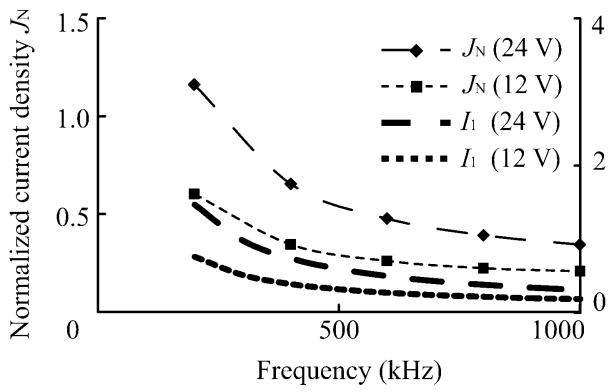

(c)

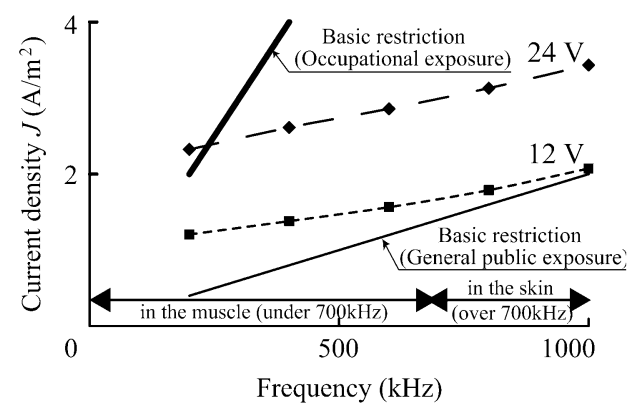

(b)

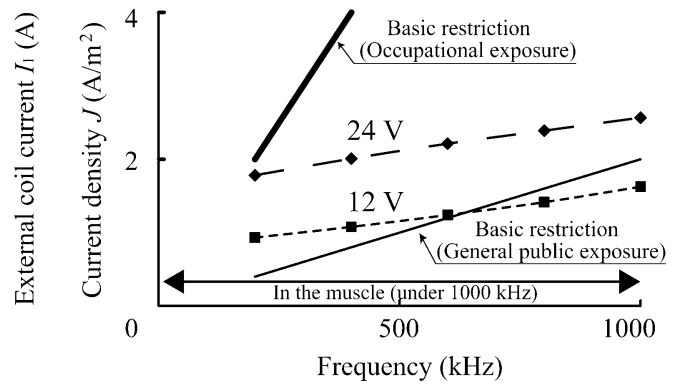

(d)

Fig. 11. (a) Maximum current density as a function of the output power. (b) Maximum current density as a function of the frequency. (c) Normalized current density as a function of the frequency. (d) Maximum current density as a function of the frequency with larger model.

dashed line indicates an output voltage of $24 \mathrm{~V}$, the short dashed line indicates an output voltage of $12 \mathrm{~V}$ and the full line indicates the basic restrictions. As for the results under $700 \mathrm{kHz}$, the current density is maximized in the muscle layer at a distance of $20 \mathrm{~mm}$ from the body's surface. With regard to the results over $700 \mathrm{kHz}$, the current density is maximized in the skin layer at a distance of $5 \mathrm{~mm}$ from the body's surface. Also, the current density gets larger as the frequency and output voltage rise. To consider the ICNIRP's basic restrictions, high frequency and low output voltage are safe conditions to transfer energy. This coil exceeds the basic restriction for occupational exposure when the frequencies are less than $250 \mathrm{kHz}$ at the output voltage of $24 \mathrm{~V}$, however; therefore, it needs to reduce the current density even further. The current density divided by the basic restrictions for occupational exposure is investigated here and is shown with the external coil's current in Fig. 11(c). The long dashed line and short dashed line with thick lines show the external coil's current when the output voltage is 24 and $12 \mathrm{~V}$, respectively. The normalized current density is safe when the value is under 1 , on the condition of over $200 \mathrm{kHz}$ at the output voltage of $12 \mathrm{~V}$, or over $250 \mathrm{kHz}$ at the output voltage of $24 \mathrm{~V}$. Comparing the results of normalized current density with the external coil's current, their slopes correspond very well. This suggests that a decrease in the external coil's current causes the reduction of the normalized current density.

3) Analysis When the Coil's Diameter Is Varied: The external coil's current is directly proportional to the output voltage, and is inversely proportional to the frequency and to the mutual inductance between the coils. Hence, reducing the external coil's current requires the following conditions: a) reducing the output voltage; b) increasing the frequency; and c) increasing the mutual inductance. The conditions of a) and b) are already confirmed in Section III-C2). Therefore, in order to increase the mutual inductance, a model whose transcutaneous transformer's dimensions were multiplied by 1.1 was analyzed (large model: the external coil's diameter is $100 \mathrm{~mm}$ and the internal coil's is $70 \mathrm{~mm}$ ).

The analytical results of the maximum current density as a function of each frequency are shown in Fig. 11(d). As for the results, the current density is maximized in the muscle layer at a distance of $20 \mathrm{~mm}$ from the body's surface. Also, as these results show, the current density was reduced compared to Fig. 11(b). The safe available frequency ranges are extended as the current density falls from a frequency of over $250 \mathrm{kHz}$ in Fig. 11(b) to a frequency of over $150 \mathrm{kHz}$ in Fig. 11(d). Therefore, it is confirmed that making the coil diameter larger effectively reduces current density. In addition, it is confirmed that the normalized current density is directly proportional to the external coil's current, and that the current density could be lowered by designing an external coil with a lower current.

\section{Design of a Safe Coil}

As the analytical results of primary Section III show, it is clear that frequency $f$, output voltage $V_{2}$, mutual inductance $M$, and coil diameter are important parameters for the design of safe transmission. This secondary section proposes four types of safe and high efficiency transmission transformer: $V_{2}=24 \mathrm{~V}$, $f=500-700 \mathrm{kHz}$ in the basic model; Type $\mathrm{A}, V_{2}=12 \mathrm{~V}$, $f=200-300 \mathrm{kHz}$ in the basic model; Type $\mathrm{B}, V_{2}=24 \mathrm{~V}$, $f=300-400 \mathrm{kHz}$ in the larger model; Type $\mathrm{C}$, and $V_{2}=12$ $\mathrm{V}, f=200 \mathrm{kHz}$ in the larger model; Type D (cf. Table II). Here, the frequency range meets the following conditions: SAR and current density are below the ICNIRP's basic restrictions and the efficiency is over $90 \%$. These four models' transmission efficiency is analyzed and measured by a digital power meter (Yokogawa, PZ4000). The results are shown in Table II and the efficiency is over $90 \%$. It is possible to use these conditions for the TETS 
TABLE II

SAFE Available FreQuency RANGes AND THE MEASURED RESULTS OF EFFICIENCY

\begin{tabular}{ccccc}
\hline \hline & \multicolumn{2}{c}{ Basic model } & \multicolumn{2}{c}{ Larger model } \\
& $($ Type A) & $($ Type B) & (Type C) & (Type D) \\
\hline Output voltage (V) & 24 & 12 & 24 & 12 \\
Frequency (kHz) & $500-700$ & $200-300$ & $300-400$ & 200 \\
Efficiency (\%) & 94.3 & 93.1 & 95.7 & 93.1 \\
\hline \hline
\end{tabular}

\section{CONCLUSION}

We have analyzed the SAR and current density in biological tissue surrounding a transcutaneous transformer, and examined the transmission frequency, output voltage, output power, and coil's dimensions.

According to the results, the SAR's values get smaller as the output voltage and transmission frequency become lower and the coil's dimensions increase. The SAR is not changed by output power. The proportions of SAR values in the skin, fat, and muscle are about 3:2:1, but between frequencies of 100 and $1000 \mathrm{kHz}$ the SAR in the skin layer is so small compared to the basic restrictions that there is no problem in the biological tissue with transferring energy. In addition, we have confirmed that the temperature of coils during energy transmission in the small water bath at a constant temperature of $37{ }^{\circ} \mathrm{C}$ is about $40.5^{\circ} \mathrm{C}$, which is below the temperature, $41^{\circ} \mathrm{C}$, that negatively influences biological tissue [37], [38]. The temperature rise of coils by SAR is only $0.035{ }^{\circ} \mathrm{C}$ calculated by SAR of $0.4 \mathrm{~W} / \mathrm{kg}$ equal to the body temperature rise of $1{ }^{\circ} \mathrm{C}$ [14], and it is obvious that the temperature rise of a transcutaneous transformer is much larger.

While the results of normalized current density gets smaller as the frequency rises and the output voltage falls, these conditions make it possible to transfer energy with little influence. Also, the current density is small when the coil's dimension increases. However, the current density is not changed by the output power. This is because the generated magnetic field gets smaller due to the external coil's current getting smaller when the output voltage is low, the frequency is high and the mutual inductance is large. In consideration of the current density of the skin, fat, and muscle, the current density in the fat layer is about one-tenth of that in the skin layer between the frequencies of 100 and $1000 \mathrm{kHz}$. The current density in the muscle layer is large compared to the skin layer less than $700 \mathrm{kHz}$, but is small over $700 \mathrm{kHz}$. In other words, the part of the biological tissue that maximized the current density differed by frequency. These are very interesting results, and mean that correct results cannot be obtained if the frequency characteristic and type of biological tissue are not imitated correctly. Therefore, the results in this paper will be very valuable data, not only for artificial hearts, but also for other implanted devices with the TET system.

In the future, animal experiments will be performed and evaluated with coils that account for the transmission characteristics and safety.

\section{ACKNOWLEDGMENT}

The authors would like to thank Y. Hasegawa and N. Kuwano of Flomerics (Japan branch) for their useful suggestions and support with regard to the electromagnetic simulator.

\section{REFERENCES}

[1] W. J. Kolff, T. Akutsu, B. Dreyer, and H. Norton, "Artificial heart in the chest and use of polyurethane for making hearts, valves and aortas," Trans. Amer. Soc. Artif. Int. Organs, vol. 5, pp. 298-300, 1959.

[2] E. Tatsumi, Y. Taenaka, A. Homma, T. Nishinaka, Y. Takewa, T. Tsukiya, H. Ohnishi, M. Oshikawa, Y. Shirakawa, Y. Kakuta, K. Shioya, N. Katagiri, T. Mizuno, T. Kamimura, H. Takano, K. Tsukahara, K. Tsuchimoto, H. Wakui, and H. Yamaguchi, "The national cardiovascular center electrohydraulic total artificial heart and ventricular assist device systems: Current status of development," ASAIO J., vol. 49, pp. 243-249, 2003.

[3] Y. Mitamura and S. Murabayashi, "The Japanese artificial organs scene: Current status," Artificial Organs, vol. 29, no. 8, pp. 675-680, 2005.

[4] J. C. Schuder, H. E. Stephenson, Jr., and J. F. Townsend, "Energy transfer into a closed chest by means of stationary coupling coils and a portable high-power oscillator," Trans. Amer. Soc. Artif. Int. Organs, vol. 7, pp. 327-331, 1961.

[5] K. Koshiji, T. Utsunomiya, S. Takatani, H. Takano, T. Nakatani, M. Kinoshita, H. Noda, S. Fukuda, and T. Akutsu, "Analysis of efficiency and experimental consideration of energy transmission system to drive total implanted artificial heart," Japan. J. Artif. Organs, vol. 16, no. 1, pp. $167-170,1987$.

[6] K. Koshiji, K. Masuda, E. Shu, T. Utsunomiya, S. Takatani, H. Takano, and T. Akutsu, "Development of transcutaneous energy transmission system for totally implantable artificial heart," Japan J. Artif. Organs, vol. 18 , no. 2 , pp. 533-536, 1989.

[7] Y. Abe, I. Fujimasa, K. Imachi, M. Nakajima, K. Mabuchi, T. Chinzei, K. Maeda, Y. Orime, M. Asano, H. Hata, S. Hosaka, A. Kouno, T. Ono, and K. Atsumi, "Development of transcutaneous energy transmission system for totally implantable artificial heart: Effect of coreless coils," Japan J. Artif. Organs, vol. 16, no. 1, pp. 212-215, 1987.

[8] T. Mussivand, A. Hum, M. Diguer, K. S. Holmes, G. Vecchio, R. G. Masters, P. J. Hendry, and W. J. Keon, "A transcutaneous energy and information transfer system for implanted medical devices," ASAIO J., vol. 41, no. 3, pp. M253-M258, 1995.

[9] K. Shiba, M. Nukaya, T. Tsuji, and K. Koshiji, "An air-core transcutaneous energy transmission system for an artificial heart- controlling and stabilizing the output voltage using external information," Trans. Japanese Soc. Medical Bio. Eng., vol. 43, no. 4, pp. 670-676, 2005.

[10] H. Matsuki, "Energy transfer system utilizing amorphous wires for implantable medical devices," IEEE Trans. Magn., vol. 31, no. 2, pp. 1276-1282, Feb. 1995.

[11] K. Shiba, E. Shu, K. Koshiji, K. Tsukahara, K. Tsuchimoto, T. Ohumi, T. Nakamura, S. Endo, T. Masuzawa, E. Tatsumi, Y. Taenaka, and H. Takano, "Efficiency improvement and in vivo estimation of externally-coupled transcuteneous energy transmission system for a totally implantable artificial heart," in Proc.19th Ann. Int. Conf. IEEE Eng. Med. Bio. Soc., 1997, pp. 2503-2505.

[12] J. C. Schuder, "Powering an artificial heart: Birth of the inductively coupled-radio frequency system in 1960," Artif. Organs, vol. 26, no. 11, pp. 909-915, 2002.

[13] S. Nitta, Y. Kami, Y. Sato, K. Sugiura, N. Seto, and O. Fujiwara, Electromagnetic Compatibility Handbook. Tokyo: Asakura Publishers, 1999.

[14] International Commission on Non-Ionizing Radiation Protection, "Guidelines for Limiting Exposure to Time-Varying Electric, Magnetic, and Electromagnetic Fields (up to $300 \mathrm{GHz}$ )," Health Phys., vol. 74, no. 4, pp. 494-522, 1998.

[15] K. Shiba, K. Koshiji, E. Tatsumi, Y. Taenaka, and H. Takano, "Analysis of specific absorption rate in biological tissue surrounding transcutaneous transformer for an artificial heart," J. Artif. Organs, vol. 5, no. 2, pp. 91-96, 2002.

[16] H. Honda, K. Shiba, E. Shu, K. Koshiji, T. Murai, T. Nakamura, T. Masuzawa, E. Tatusmi, Y. Taenaka, and H. Takano, "Selection of a rechargeable internal back-up battery for a totally implantable artificial heart," J. Amer. Soc. Artif. Int. Organs, vol. 45, no. 4, pp. 339-343, Jul./Aug. 1999 
[17] K. Shiba, E. Shu, K. Koshiji, K. Tsukahara, T. Nakamura, T. Masuzawa, E. Tatsumi, Y. Taenaka, and H. Takano, "A transcutaneous energy transmission system with rechargeable internal back-up battery for a totally implantable total artificial heart," J. Amer. Soc. Artif. Int. Organs, vol. 45, no. 5, pp. 466-470, Sep./Oct. 1999.

[18] M. Nukaya, A. Sakane, K. Shiba, and T. Tsuji, "Transcutaneous energy transmission system for an artificial heart- improvement of the transmitting efficiency in various load resistance," in Proc. 55th ChugokuSection Joint Convention Record Inst. Elect. Inf. Eng., Oct. 2004, pp. 189-190.

[19] V. Hombach, K. Meier, M. Burkhardt, E. Kuhn, and N. Kuster, "The dependence of EM energy absorption upon human head modeling at 900 MHz," IEEE Trans. Microw. Theory Technol., vol. 44, no. 10, pp. 1865-1873, Oct. 1996.

[20] T. Kobayashi, T. Nojima, K. Yamada, and S. Uebayashi, "Dry phantom of ceramics and its application to SAR estimation," IEEE Trans. Microw. Theory Technol., vol. 41, no. 1, pp. 136-140, Jan. 1993.

[21] J. P. Reilly, "Peripheral nerve stimulation by induced electric currents: Exposure to time-varying magnetic fields," Med. Bio. Eng. Comput., vol. 27, pp. 101-110, 1989.

[22] J. H. Bernhardt, "The establishment of frequency dependent limits for electric and magnetic fields and evaluation of indirect effects," Radiat Environ. Biophys., vol. 27, pp. 1-27, 1988.

[23] H. Endo, K. Shimizu, and G. Matsumoto, "Measurement of distribution of ELF electric field and induced current at human body," IEE J. High Voltage Eng., pp. 29-38, 1986, HV-86-71.

[24] C. Christos, The Transmission-Line Modeling Method. Piscataway, NJ: IEEE Press, 1995.

[25] Y. Kagawa, N. Yoshida, T. Tsuchiya, and M. Sato, Introduction to Equivalent Network Method. Tokyo: Morikita Shuppan Co., Ltd., 2000.

[26] M. Krumpholz and P. Russer, "A field theoretical derivation of TLM," IEEE Trans. Microw. Theory Technol., vol. 42, no. 9, pp. 1660-1668, Sep. 1994.

[27] "Research institute of human engineering for quality life,", Osaka, Japan, Japanese body size date 1992-1994 1997.

[28] D. Andreuccetti, R. Fossi, and C. Petrucci, "Calculation of the dielectric properties of body tissues in the frequency range $10 \mathrm{~Hz}-100$ GHz,” Inst. Appl. Phys., Florence, Italy, 2007 [Online]. Available: http://niremf.ifac.cnr.it/tissprop/htmlclie/htmlclie.htm\#atsftag

[29] C. Gabriel, S. Gabriel, and E. Corthout, "The dielectric properties of biological tissues: I. Literature survey," Phys. Med. Bio., vol. 41, pp. 2231-2249, 1996.

[30] S. Gabriel, R. W. Lau, and C. Gabriel, "The dielectric properties of biological tissues: II. Measurements in the frequency range $10 \mathrm{~Hz}$ to 20 GHz," Phys. Med. Bio., vol. 41, pp. 2251-2269, 1996.

[31] S. Gabriel, R. W. Lau, and C. Gabriel, "The dielectric properties of biological tissues: III. Parametric models for the dielectric spectrum of tissues," Phys. Med. Bio., vol. 41, pp. 2271-2293, 1996.

[32] "Japan Society of Medical Electronics and Biological Engineering," in Handbook of Clinical Engineering. Tokyo, Japan: Corona Publishers, 1984.

[33] Y. Okano, K. Ito, I. Ida, and M. Takahashi, "The SAR evaluation method by a combination of thermographic experiments and biological tissue-equivalent phantoms," IEEE Trans. Microw. Theory Technol., vol. 48, no. 11, pp. 2094-2103, Nov. 2000.

[34] B. R. Epstein and K. R. Foster, "Anisotropy in the dielectric properties of skeletal muscle," Med. Bio. Eng. Comput., vol. 21, pp. 51-55, 1983.

[35] F. L. H. Gielen, W. Wallinga-de Jonge, and K. L. Boon, "Electrical conductivity of skeletal muscle tissue: Experimental results from different muscles in vivo," Med. Bio. Eng., vol. 22, pp. 569-577, 1984.

[36] D. Stoy, K. R. Foster, and H. P. Schwan, "Dielectric properties of mammalian tissues from 0.1 to $100 \mathrm{MHz}$ : A summary of recent data," Phys. Med. Bio., vol. 27, no. 4, pp. 501-513, 1982.

[37] H. Emoto, H. Harasaki, L. K. Fujimoto, R. R. Navarro, M. White, R. Whalen, R. J. Kiraly, and Y. Nose, "Systemic and local effects of heat dissipation in the thermally powered LVAS," Trans. Amer. Soc. Artif. Int. Organs, vol. 34, pp. 361-366, 1988.

[38] H. Harasaki, C. Davies, K. Nakamura, T. Matsuyoshi, and K. Fukumachi, "Safe temperature thresholds for implantable artificial heart," presented at the Proc. 6th Int. Symp. Artif. Heart Assist Devices, Progr. Abstracts, Tokyo, Japan, 1996.

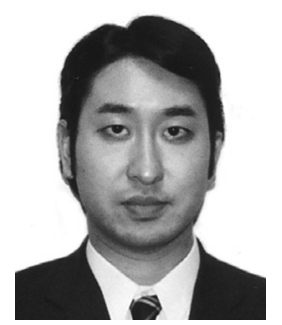

Kenji Shiba received the B.E., M.E., and D.E. degrees in electrical engineering from Tokyo University of Science, Chiba, Japan, in 1995, 1997, and 2000, respectively.

He is currently an Associate Professor with the Department of Artificial Complex Systems Engineering, Hiroshima University, Hiroshima, Japan. From 2000 to 2001, he was a Research Fellow with the Japan Society for the Promotion of Science, Tokyo, Japan. In 2001, he was a Research Associate with the Department of Human and Engineered Environmental Studies, the University of Tokyo, Tokyo, Japan. His current research interests include the development of implantable medical devices, bioelectromagnetics, and electromagnetic compatibility.

Dr. Shiba was a recipient of the Best Paper Award from the Japanese Society for Artificial Organs in 2001. He is a member of the Japanese Society for Artificial Organs, the Japan Society of Medical Electronics and Biological Engineering, the IEEE Engineering in Medicine and Biology Society, and the IEEE Electromagnetic Compatibility Society.

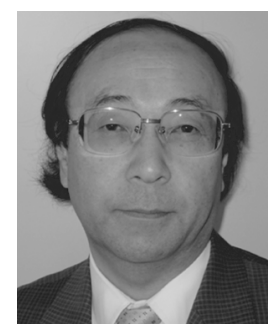

Kohji Koshiji received the D.E. degree in electrical engineering from Tokyo University of Science, Chiba, Japan, in 1978.

Currently, he is a Professor with the Department of Electrical Engineering, Tokyo University of Science. His research interests include biomedical engineering, biomaterial studies, analysis and design of microwave circuit, and analysis and design of electronic equipment considering electromagnetic compatibility. He is a member of the Institute of Electronics, Information and Communication Engineers (IEICE), the Japanese Society for Artificial Organs (JSAO), the American Society for Artificial Internal Organs (ASAIO), the IEEE Engineering in Medicine and Biology Society, and the IEEE Electromagnetic Compatibility Society.

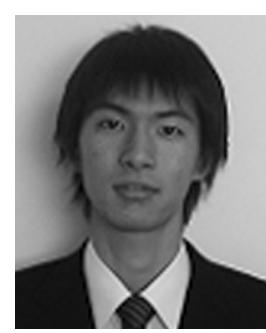

Masayuki Nukaya received the B.E. degree in electrical, computer, and systems engineering and the M.E. degree in artificial complex systems engineering from Hiroshima University, Japan, in 2005 and 2007, respectively.

His research interests includes transcutaneous energy transmission system for an artificial heart.

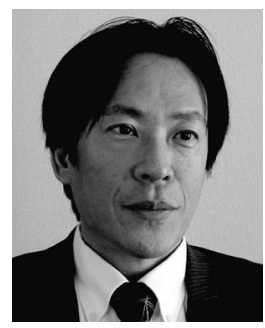

Toshio Tsuji received the B.E. degree in industrial engineering and the M.E. and Doctorate of Engineering degrees in systems engineering from Hiroshima University, in 1982, 1985, and 1989, respectively.

He was a Research Associate from 1985 to 1994 and an Associate Professor, from 1994 to 2002, with the Faculty of Engineering, Hiroshima University. From 1992 to 1993, he was a Visiting Professor with the University of Genova, Genova, Italy. He is currently a Professor with the Department of Artificial Complex Systems Engineering, Hiroshima University. His current research interests focus on human-machine interface, and computational neural sciences, in particular, biological motor control.

Dr. Tsuji was a recipient of a Best Paper Award from The Society of Instrumentation and Control Engineers in 2002 and the K. S. Fu Memorial Best Transactions Paper Award of the IEEE Robotics and Automation Society in 2003. He is a member of the Institute of Electrical and Electronics Engineers, the Japan Society of Mechanical Engineers, the Robotics Society of Japan, and the Society of Instrumentation and Control Engineers in Japan. 